\title{
OS SUPOSTOS ESPAÇOS DE DISCUSSÃO FUTEBOLÍSTICA NA TELEVISÃO: AS "MESAS REDONDAS"
}

\author{
MS. THIAGO ARAGÃO ESCHER \\ Doutorando em Educação pela Universidade Estadual de Campinas (Unicamp); \\ Faculdade de Educação - Unicamp; Faculdade de Jaguariúna (FAJ) \\ (Campinas - São Paulo - Brasil) \\ E-mail:thiaragao@yahoo.com.br
}

DRA. HELOISA HELENA BALDY DOS REIS

Livre-docente em Educação Física pela Faculdade de

Educação Física da Universidade Estadual de Campinas

Professora Associada da FEF/UNICAMP

(Campinas - São Paulo - Brasil)

E-mail:heloreis@fef.unicamp.br

\begin{abstract}
RESUMO
Este artigo analisa os programas esportivos que supostamente são os espaços de discussão do futebol. Para tanto, escolhemos os programas "Terceiro Tempo", da Rede Bandeirantes de Televisão e "Mesa Redonda", da TV Gazeta, por serem os mais relevantes do gênero e por serem constantemente citados nas respostas dos entrevistados de Reis (2008). Analisamos a estrutura de apresentação dos programas veiculados no ano de 2008, durante a realização do Campeonato Brasileiro de futebol, principalmente sua composição com o merchandising. Conclui-se que a compreensão desse processo não deve ser visto como uma mera mercadorização do esporte, e sim como uma mistura entre o processo simbólico que existe no futebol e sua latente transformação em mercadoria, que contribui também para uma visão fragmentada da violência no futebol e dos torcedores.
\end{abstract}

PALAVRAS-CHAVE: Futebol; televisão; programas esportivos; merchandising. 
Este trabalho faz parte de uma pesquisa realizada no ano de 2008 ', com as principais torcidas organizadas do Estado de São Paulo². Faremos neste trabalho uma análise dos programas esportivos que supostamente são os espaços de discussão do futebol. Para tanto, escolhemos os programas "Terceiro Tempo", da Rede Bandeirantes de Televisão (TV Band) e "Mesa Redonda", da TV Gazeta.

Escolhemos esses programas por serem os mais significativos na Rede Aberta dos canais televisivos, durante o ano de 2008 (durante a realização do campeonato brasileiro), além de terem sido constantemente citados pelos torcedores nas entrevistas realizadas para identificar o perfil dos torcedores organizados da cidade de São Paulo (REIS, 2008). Os nomes dos jornalistas envolvidos nos programas foram citados, assim como a própria dinâmica dos programas, como fatores que influenciam na violência no futebol. Apesar dos programas analisados terem uma audiência pouco expressiva para as redes de televisão e para seus anunciantes, principalmente se comparados aos jogos importantes que são transmitidos, ou a outros programas não esportivos. Corroboramos com Toledo (2002), quando ele diz que é necessário considerar que estes possuem um público fiel e considerável, e que há uma enorme repercussão de suas imagens e comentários, conforme esta pesquisa.

As "mesas redondas", como são conhecidos os programas desse formato, são os supostos espaços de discussão do futebol no Brasil. Geralmente ocorrem após as rodadas dos fins de semana, e são responsáveis por maximizar o jogo em si e por contribuir com a criação da "falação" esportiva. Como nos lembra Eco ( 1984), essa "falação" esportiva potencializa-se quando as discussões feitas na televisão advêm de imagens televisivas que não correspondem à realidade, e as pessoas comentam com base nessas discussões, ficando cada vez mais distantes do que realmente aconteceu dentro do estádio, agindo cada vez menos autonomamente em relação à "falação" televisiva.

Os procedimentos metodológicos utilizados para a coleta e análise dos programas esportivos estudados foram: I gravação dos referidos programas durante todo o Campeonato Brasileiro de 2008 2. assistência dos programas pelos pesquisadores por duas vezes; 3. elaboração de roteiro de análise dos mesmos - quanto a sua estrutura; 3. novas assistências, para análise das categorias criadas e para a seleção de frases significativas para a pesquisa.

I. A pesquisa foi financiada pelo Ministério do Esporte por meio de aprovação da pesquisa denominada "A caracterização do torcedor organizado e a mídia esportiva" contemplado no edital de 29/03/2007, processo n. 58701.000196/2007-8, esta inseriu a Faculdade de Educação Física da Unicamp na Rede CEDES.

2. Aprovado pelo Comitê de Ética em Pesquisa da Unicamp, sob n. CEP 322/2007. 
As entrevistas utilizadas neste artigo fazem parte da pesquisa de Reis (2008), realizada durante os campeonatos Copa do Brasil e Campeonato Brasileiro de Futebol de 2008, em jogos em que os torcedores organizados entrevistados eram pertencentes às equipes mandantes do jogo. Nestas, foi perguntado a 804 associados de três grandes torcidas organizadas de São Paulo: I. quais motivos da violência em dias de jogos?; 2. se a mídia, de um modo geral (jornais e TV), contribui para a violência em dias de jogos? Do universo de entrevistados, 797 responderam estas questões. Para a realização das entrevistas, havia um roteiro de perguntas fechadas e três abertas. As tratadas neste artigo fazem parte das questões abertas. As entrevistas foram realizadas com uma equipe de 14 estudantes de graduação e de pós-graduação da Unicamp. ${ }^{3}$

\section{POR DENTRO DAS MESAS}

Segundo Toledo (2002), é nas mesas redondas que se reúnem as opiniões dos profissionais e dos especialistas, com o domínio desses últimos, para ler os jogos à distância, longe das torcidas, distante do ritual futebolístico e do fluxo emocional das partidas ao vivo. Seria, portanto, o lugar para reflexões mais frias e técnicas, proferidas principalmente pelos especialistas, que se outorgariam uma autoridade exatamente por diferir das opiniões emocionais dos torcedores. No entanto, a entonação dos programas, a informalidade das falas e a falta de consenso planejada promovem uma aproximação com a linguagem dos torcedores, colaborando ainda mais para a potencialização da "falação" esportiva. A semelhança das discussões/ linguagem dos especialistas com as proferidas por torcedores em bares e em locais onde se discute o futebol, contribui para a identificação e manutenção dos torcedores em frente a TV. O futebol que é jogado nos campos, é transmitido pela televisão, criando dessa forma uma "realidade relativamente autônoma" (BETTI, 1998), Nestes programas ele era comentado a partir das imagens televisivas, portanto, a partir dessa "realidade relativamente autônoma", e que, ao final, era comentado pelos torcedores, baseado nos comentários proferidos anteriormente pelos especialistas, o que distancia substancialmente daquele futebol primordialmente jogado nos campos. Conforme afirmam Freitas e Rigo (2009, p. I I6), "os tipos de discursos que esse campo produz [midiático], multiplica e faz proliferar, bem como os efeitos de verdade apresentados por esses discursos."

Os dois programas escolhidos serão rapidamente descritos para um melhor entendimento da análise realizada na pesquisa:

3. Sob coordenação e supervisão da Profa ${ }^{a}$. Dra. Heloisa Helena Baldy dos Reis, para o tratamento estatístico dos dados sobre a mídia e a violência foi obtido dados em 797 entrevistas. 
Programa dominical que ocorre, geralmente, após o término das partidas do fim de semana. Ela era composta pelo apresentador Flávio Prado e pelos jornalistas Wanderlei Nogueira, Dalmo Pessoa, Chico Lang e Fernando Sólera. Além destes, sempre há a presença de ao menos dois convidados, entre jogadores, ex-jogadores, treinadores, dirigentes etc.

Há também uma presença feminina, a da jornalista Michelle Giannella, e sua participação se resume a ler os comentários dos participantes telespectadores que enviam suas mensagens via Internet, ou então da enquete que o programa proporciona.

Esse programa é marcado pela centralização em seu apresentador, que comanda a discussão e as perguntas aos convidados. Como a maioria dos programas desse formato (mesas redondas), cabe ao apresentador dar a dinâmica das discussões, suscitar reclamações e, principalmente, criar polêmica. Ao jornalista Chico Lang é cabido o papel de desenvolver as polêmicas, geralmente com exaltações e com opiniões bastante controversas. O jornalista Dalmo Pessoa é o responsável pelas considerações ponderadas e pelo jornalismo menos passional do programa. Os jornalistas Wanderlei Nogueira e Fernando Sólera têm pouca participação, se assemelhando mais às ponderações de Dalmo Pessoa.

É importante salientar que o formato das mesas redondas propicia um debate entre os "especialistas" e os "profissionais", tentando dar a sensação de uma conversa informal, que supostamente poderia ser realizada em qualquer roda de bar, com a diferença de poder ser assistido por todo o país. A linguagem se assemelha às conversas informais, e a transposição de falas é corrente.

O programa possui duas horas e meia de duração, iniciando às $21: 30 \mathrm{~h}$ e terminando 00:00h. Possui geralmente três intervalos comerciais, um a menos que o programa "Terceiro Tempo", porém "compensa" com mais produtos sendo apresentados via merchandising. Aliás, esses parecem ser a grande tônica do programa. Em média, o programa é interrompido 10 vezes para o anúncio de alguma mercadoria, que vai desde restaurantes, lojas de carros, marcas de calçados, tubos e conexões, etc, até anúncios da Previdência Social. Os formatos dos merchandising variam, podendo ser uma simples fala do apresentador ou dos jornalistas, ou uma

4. Termos construídos por Toledo (2002, p. I 60) ao tratar do "campo" do futebol. Os especialistas são aqueles que, apesar de não configurar um grupo homogêneo, "apresenta-se como portadora de um conjunto articulado de representações, fixadas em discursos, saberes e práticas diferenciados, contrapostas às dos torcedores e profissionais", que seriam aqueles que vivenciam diretamente o "campo" do futebol, como jogadores, técnicos e dirigentes. 
entrada de algum personagem anunciante de algum produto, ou mesmo a interferência de algum filme publicitário. Na média dos programas analisados, há quase I 4 minutos de merchandising por programa, o que equivale a aproximadamente $10 \%$ do programa. Se juntarmos esse tempo com o intervalo comercial, teremos em média 3 I minutos de anúncios publicitários, ou seja, aproximadamente $20 \%$ do total.

O programa também é marcado por imagens dos gols da rodada e por reportagens dos clubes paulistas. Apesar de ser transmitido em todo o país, o programa se resume a matérias sobre os quatro principais clubes do Estado de São Paulo (Corinthians, Palmeiras, Santos e São Paulo).

\section{PROGRAMA TERCEIRO TEMPO - REDE BANDEIRANTES DE TELEVISÃO}

Programa também dominical, que concorre com a Mesa Redonda da TV Gazeta. Ele era composto pelo apresentador Milton Neves, pelos jornalistas Oscar Godoy, Mauro Betting, Paulo Morça e, geralmente, três convidados entre os "profissionais" do futebol. Não há presença feminina no programa, nem mesmo para a leitura dos e-mails. Os comentários masculinizados e o tom machista são freqüentes.

O programa é centralizado em seu apresentador, que é o grande responsável por incitar as (falsas?) discussões. Cabe ao jornalista Paulo Morça desenvolver as discussões, sendo geralmente contrário às opiniões do apresentador. Ao jornalista Oscar Godoy, ex-árbitro de futebol, cabe os comentários supostamente técnicos em relação à arbitragem dos jogos da rodada, mostrando os lances polêmicos e comentando as imagens da rodada. Este inclusive é um recurso corrente no programa, sendo o "professor" Godoy (como ele é ocasionalmente nomeado por Milton Neves) chamado para discutir algum lance polêmico. $\bigcirc$ jornalista Mauro Betting tem o papel de dar explicações técnico-táticas das partidas.

O programa possui $02 \mathrm{~h}$ de duração, tendo início às $2 \mathrm{Ih}$ :30min. e término às 23h:30min. É apresentado, portanto, após o término da rodada do fim de semana. Por possuir, conjuntamente com a Rede Globo de Televisão, o direito de transmissão das partidas daquele campeonato, havia mais imagens dos jogos disputados e mais comentários em cima de imagens, do que o programa da TV Gazeta. O programa possui quatro intervalos comerciais, porém também apresenta merchandising durante o programa, que anuncia marca de cerveja, banco, cartão de crédito, e até o próprio site do apresentador. Em média, durante os programas analisados, verificamos que há seis interrupções durante o programa, para anúncio publicitário, que correspondem a oito minutos, ou seja, aproximadamente $7 \%$ do programa. Se adicionados aos intervalos comerciais, teremos mais de 22 minutos de publicidade, ou seja, aproximadamente $18 \%$ do total. 
A televisão, em especial as transmissões esportivas e seus supostos espaços de discussão, pode ser considerada como um "campo" para Bourdieu (1 983), ou seja, como um espaço estruturado, cujas propriedades dependem das posições nestes espaços, como o caso dos comentaristas, jornalistas e apresentadores, mas que podem ser analisadas independentemente das características dos seus ocupantes.

Assim, ao estudarmos os programas esportivos, consideramos os mesmos como um campo que possui leis invariantes, gerais, que fazem parte de um contexto amplo inserido em determinada sociedade e que, atualmente, sofre fortes influências da globalização. No entanto, ao se analisar, conhece-se suas propriedades específicas, próprias do seu campo particular, que inviabiliza, muitas vezes, generalizações para todo o campo da sociedade, ou mesmo para todo o campo midiático.

É desta forma, por exemplo, que foi analisada a forte presença do merchandising ${ }^{5}$ nos programas estudados. A entrada desse mecanismo publicitário nesses programas esportivos demonstra mais explicitamente a relação entre o esporte, a televisão e a dependência das leis de mercado. A mercadorização de produtos durante os programas esportivos causou, inclusive, um grande "racha" entre os principais jornalistas esportivos. De um lado, os defensores do merchandising tornando-se garotos-propaganda de diversos produtos e incrementando seus ganhos no final do mês. De outro lado, os defensores de uma ética profissional nos programas esportivos, e de uma relativa autonomia entre seus comentários e a venda dos produtos.

Nessas mesas redondas é explícita a utilização de um espaço esportivo para a venda de mercadorias. Os dois programas analisados utilizaram-se, em grande escala, do recurso do merchandising. Qualquer discussão existente pode ser paralisada para dar entrada à exposição de algum produto. No meio de discussões acaloradas, em várias ocasiões com exaltações dos participantes, era necessária a interrupção destas para o anúncio de aspirador de pó, carro, cerveja ou tubos de PVC. O apresentador dizia:

"Daqui a pouco a gente fala mais do Corinthians, agora vou falar de uma coisa importante: A JMC elétricas..."

"Chico, você tem um recado importante para o torcedor?

5. Propaganda televisiva feita durante o próprio programa, não mais nos intervalos comerciais, utilizando muitas vezes o próprio apresentador do programa, ou seus comentaristas, como "vendedores" do produto. 
— Sim, a Ypioca é uma cachaça de qualidade..."

"Queria cumprimentar os patrocinadores dos esportistas brasileiros! Parabéns ao Bradesco, ao Pão de Açúcar..."

"Olha Chico, falávamos de carro, eu que não tenho pneu para rodar na Turquia, como posso fazer?

_ Olha, quem quiser pode ir a loja..."

"Em nome da Brahma voltaremos semana que vem! Em nome da Brahma tem tudo!

Essas e diversas outras manifestações tentaram relacionar a imagem do esporte com os produtos veiculados, estratégia utilizada em 10\% do tempo total do programa. A grande discussão, despertada dessa relação, é a credibilidade dos jornalistas e do próprio programa, ao anunciarem esses produtos. A compreensão desse processo não deve ser vista como uma mera mercadorização do esporte, e sim como uma mistura entre o processo simbólico que existe no futebol, e sua latente transformação em mercadoria. O público que assiste a esses programas, não os assistem, obviamente, para poder ver seus anúncios publicitários, o que viabiliza manobras de persuasão mercadológicas, para não tornar o programa monótono e não atraente para os telespectadores.

Quando as programações esportivas televisivas se voltam exclusivamente aos interesses da audiência, ou seja, aos interesses do mercado, as relações com os telespectadores geralmente não passam de pontos que serão medidos pelo lbope. Mesmo com todas as possibilidades de medição, não deixa de ser uma relação impessoal, que visa atingir uma grande maioria, uma massa homogeneizada. Parte-se de pressupostos de que todos os telespectadores gostariam de assistir e, desta forma, repete-se o modelo de sucesso (aqui considerado como programas de boa audiência e, consequentemente, de bons contratos publicitários) até sua exaustão (perda da boa audiência), restando na verdade pouca opção de escolha aos que assistem as redes de televisão aberta.

No entanto, os programas não podem conter, em sua maior parte, anúncios publicitários, pois correm o risco de perder seus fiéis telespectadores para algum outro canal, o que contraria a idéia, muito em voga, de que os torcedores estariam se tornando somente consumidores do espetáculo esportivo, em detrimento de sua paixão por determinado clube.

$\mathrm{Na}$ era da globalização e do rompimento de fronteiras, não seria descabido pensar em rompimento também das identidades regionais ou nacionais, ou então na substituição de torcedores apaixonados por seus times, por espectadores mais "frios", por "meros" consumidores do espetáculo futebolístico. 
Giulianotti (2002, p. 188), por exemplo, aproveitando-se do termo "pós-turista", criado por John Urry, cria a denominação de "pós-torcedor", que para ele seria uma nova categoria de torcedor que "[...] trabalha em escritórios, e demonstra maior capacidade de reflexão e um distanciamento crítico ao participar de uma cultura popular".

Os "pós-torcedores" na era da "pós-modernidade", conforme idéias de Giulianotti (2002), surgiriam com importantes mudanças ocorridas no futebol no período pós-industrial. Esses torcedores se caracterizariam por fazer parte de uma "nova classe média", que diferentemente da burguesia tradicional, abraça a cultura popular em vez de rejeitá-la.

Esses torcedores possuiriam um caráter mais crítico em relação ao futebol e em relação à sua apropriação pelos meios de comunicação. Com a mercadorização do futebol, seriam esses os torcedores que freqüentariam os estádios, seriam eles os novos consumidores do futebol, o que não deixaria espaços para torcedores apaixonados e para demonstrações descontroladas.

No entanto, essa análise do "pós-torcedor" comedido, apresentado por Giulianotti (2002), parece ainda não ser a totalidade dos torcedores que acompanham o futebol, principalmente quando tratamos do futebol brasileiro. A falta de evidências empíricas na obra do referido autor nos faz relativizar isso, mesmo para o futebol europeu. Até porque a violência não foi totalmente erradicada do futebol europeu, e as camadas populares, ao que parece, ainda não deixaram completamente de frequentar os estádios.

No Brasil isso fica ainda mais evidente, principalmente quando se verifica a resistência ao modelo gerencial profissional e a uma reformulação ${ }^{6}$ dos estádios. Os torcedores, no Brasil, não são vistos como potenciais consumidores do espetáculo esportivo, a não ser por meio da televisão. Dessa forma, os estádios ainda continuam precários, sem as mínimas condições para o público que os freqüentam. ${ }^{7}$

Não queremos defender a privatização dos estádios, de forma que a reformulação traga aumento dos ingressos e impossibilite que as camadas populares frequentem esses espaços de lazer. $\bigcirc$ modelo de transformação dos estádios em grandes "shopping centers"8 possui um forte caráter excludente e, apesar da possibilidade do lucro com os torcedores, não deixa de eliminar e transformar o

6. O termo "reformulação" é aqui utilizado numa tentativa de substituir o termo "modernização", que é amplamente utilizado, tanto no senso comum como no meio acadêmico. Entendemos que o termo "modernização" possui uma complexidade que poderia ser reduzida, se incorporada como simples sinônimo de remodelamento. Como não pretendemos reduzir seu significado, preferimos a utilização de outra palavra.

7. Tema já discutido, com base numa pesquisa empírica, em Escher (2004).

8. Os estádios seriam transformados em grandes centros de compras para os diversos produtos que envolvem os clubes de futebol. 
perfil deles. Entendemos que uma transformação dos estádios seja necessária, para um entendimento dos espectadores como cidadãos, que merecem ser mais bem tratados nos estádios, mas que isso não gere uma elitização no acesso aos mesmos.

Rocco Jr. (2005, p. 174) identifica uma possível tendência do futebol, em substituição às "violentas torcidas organizadas": a criação de "torcidas virtuais" (Idem), muito mais atreladas aos interesses da sociedade capitalista, pois facilitariam o controle, estimulariam o consumo e incentivariam a indústria de entretenimento.

O relacionamento do futebol com as novas tecnologias cria diversos tipos de torcedores, entre estes, os que se relacionam com seus clubes virtualmente, seja por meio da televisão, seja por sites via internet. Mas a substituição dos torcedores organizados, ou dos outros torcedores que comparecem aos estádios, que se identificam com clubes locais, por torcedores mundiais que, por meio das novas tecnologias, se comunicam e trocam ideias e opiniões em torno dos clubes, parece ainda distante de ocorrer.

As diversas manifestações ainda presentes nos estádios, assim como as constantes identificações dos torcedores com seus times e com suas torcidas organizadas, demonstram que uma transformação em torcedores mais comedidos ainda não aconteceu. Ainda como uma fonte quase exclusiva de sentido para muitas pessoas, o futebol apresenta-se como uma forma de auto-afirmação e de vivência de diversos sentimentos, para muitos torcedores. Esses, para poderem sentir-se integrados com seu time, e para sentir que fazem parte desse contexto, ainda precisam ir aos estádios, dado o isolamento resultante da assistência via televisão.

Ainda há, portanto, outras formas de torcedores, que não aquelas profeciadas pelos apocalípticos do futebol mercadoria, "frios", "comportados" e com um maior autocontrole. Da mesma forma, ainda verificamos uma heterogeneidade no campo futebolístico, ou pelo menos uma valorização das diferenças regionais, e não uma globalização e universalização verticalizada de uma determinada forma de praticar e assistir ao futebol.

A própria dinâmica dos programas analisados, que se aproxima da lógica torcedora, também é um exemplo da presença da paixão acalorada dos torcedores. Aliás, é por meio da paixão e da identificação clubística que os programas envolvem seus telespectadores.

O mecanismo utilizado pela televisão para conquistar fiéis telespectadores é o apelo à paixão clubística, é a supervalorização do sentido do futebol. $\bigcirc$ que se percebe é que a verdadeira transformação do perfil dos torcedores se dá em relação à substituição dos torcedores que frequentavam os estádios, por aqueles que acompanham seus clubes, de forma não menos apaixonada, por meio das transmissões televisivas.

As rivalidades clubísticas, por exemplo, ainda são incitadas pelos meios de comunicação, que utilizam os símbolos do clube e o sentimento de pertencimento 
de um coletivo, para garantir a audiência em seus jogos e programas. Nos dois programas analisados, os especialistas deixam isso bem claro. Com provocações (falsas?) entre os clubes, com comentários maliciosos e assumindo os clubes de preferência, eles contribuem para potencializar as rivalidades clubísticas, além de provocar reações negativas nos torcedores, como pode ser verificado nas entrevistas (REIS, 2009). Não foram raros os torcedores que criticavam os especialistas por assumirem determinadas posturas nos programas. Frases como:

"Ah, o Chico Lang é um corintiano e só fala mal dos Palmeiras!" (torcedor palmeirense, 2008)

"Pô, eles só chamam a gente de bambi e tal, aí a gente fica puto, né?" (torcedor são paulino, 2008)

"O Milton Neves só fala mal do Corinthians! Gosta de ficar zuando, põe caixão no palco quando a gente perde..." (Torcedor Corinthiano, 2008)

Na análise dos programas verifica-se a forma como a rivalidade clubística é tratada pelos especialistas. Algumas vezes em tom de brincadeira, outras falas que soam falsas e outras que parecem verdadeiras, alguns comentários deixam clara a situação de incitação das rivalidades:

"Lá em Minas só tem torcedor do Atlético" (Milton Neves, TV Band)

"Eu sempre protegi o Atlético Paranaense também" (Milton Neves, TV Band)

"O apito amigo do Corinthians, ele só ganha roubado!" (Milton Neves, TV Band)

"Vai tomar banho, rapa! Gambá, é a sua vó, zé mane!" (Chigo Lang, TV Gazeta)

"O que você tem contra o Rio e contra o Fluminense? Por que não fala deles?" (Paulo Morça, TV Band)

"Você não vê pênaltis contra o Santos? Santista de meia-tigela que você é!"

Como pudemos verificar, é por meio da exacerbação do sentido dos torcedores com seus clubes que a televisão garante audiência e possíveis consumidores para os produtos vinculados à transmissão das "mesas redondas". Diferentemente das transmissões televisivas ao vivo dos jogos, em âmbito nacional, nas quais há uma necessidade da neutralidade dos narradores (GASTALDO, 2000), ${ }^{9}$ a paixão

9. Segundo o autor, é característico das narrações futebolísticas a parcialidade dos narradores, contrariando os princípios de "neutralidade jornalística", especialmente em jogos da seleção brasileira e 
pelos clubes é a mola propulsora das "mesas redondas", na medida em que é por meio da exacerbação da identidade clubística, entendida como condição para se vivenciar plenamente a excitação futebolística ((DAMO, 2006), que se configura esses programas.

Outra característica apresentada é o não dimensionamento, proposital ou não, que alguns jornalistas esportivos possuem em relação à importância da televisão nos dias atuais, ou das suas falas e dos seus comentários. Isso fica ainda mais claro quando eles próprios relativizam seus poderes, dizendo que nada mais são do que "porta-vozes da população", e que suas ansiedades e dúvidas nada mais são que as dúvidas dos telespectadores. "O povo quer saber" ou "isso são dúvidas dos torcedores" são falas encontradas nas transmissões, que dão a impressão de que os jornalistas são realmente representantes do povo. Como não há nenhuma consulta à população, previamente, as opiniões e os questionamentos dos jornalistas nada mais são do que suas próprias dúvidas e anseios, ou então da equipe jornalística, e que na verdade colaboram muito mais para que isso se torne as dúvidas e anseios da população, do que o efeito contrário. "As necessidades do público que a televisão garante interpretar estão de fato à frente de qualquer necessidade de público que o dispositivo incorpora estruturalmente" (MATTELART, 1989, p. 172).

Com o incremento de novas tecnologias nas transmissões esportivas, há uma falsa idéia de uma maior participação dos telespectadores nas transmissões esportivas. Por meio de telefonemas, fax e, principalmente, e-mails, os telespectadores mandam mensagens e dúvidas para os jornalistas, que as lêem no programa. No programa da TV Gazeta, essa participação dos torcedores é bastante comum. Lidas pela representação feminina do programa, Michelle Gianella, que parece não poder contribuir com comentários no reduto masculino, se resumindo à leitura dos comentários e perguntas dos torcedores, dessa forma estes tem sua participação garantida no programa. Porém, é somente uma pequena minoria que consegue ter suas mensagens veiculadas, após uma seleção das mensagens que irão ser apresentadas. A mídia empresta à audiência suas próprias palavras para construir, com ela, o programa, polindo assim os procedimentos de sua legitimidade pragmática (MATTELART, 1989).

As discussões mais aprofundadas sobre o esporte e o futebol tornam-se entediantes diante de um universo unicamente preocupado em divertir a qualquer

em jogos transmitidos somente para algumas regiões. A exceção seria, portanto, os jogos transmitidos em cadeia nacional, na qual ainda há uma tentativa de imparcialidade do narrador, diferentemente das "mesas-redondas" analisadas, que também são transmitidas nacionalmente, mas que mantém o viés torcedor aflorado em todo instante. 
preço, como o desses programas, em obter prazer em qualquer relação, em espetacularizar qualquer coisa que supostamente seja pouco excitante. As imagens dos gols, das melhores jogadas, dos dribles, dos corpos que se movimentam, são muito mais palatáveis e espetaculares, e encontram maior espaço nos programas esportivos, do que discussões sobre a importância do esporte e sobre todas as suas repercussões na sociedade.

As discussões pobres nos programas analisados ficam sob a responsabilidade dos especialistas, dos comentaristas esportivos, que possuem primordialmente um discurso congruente com a lógica televisiva, em detrimento de um conhecimento do assunto. É dessa forma que, muitas vezes, esses especialistas do assunto se limitam a explicar e interpretar o que é mostrado nas imagens televisivas, criando uma versão do fato e do acontecimento, como se fossem o próprio fato e o próprio acontecimento. A autoridade a eles conferida dá a eles a impressão de serem representantes da opinião pública, outorga-lhes falar sobre qualquer acontecimento, dando suas versões sobre os fatos e suas opiniões, sem a menor preocupação com as implicações, ou mesmo com a veracidade dos fatos.

Aos telespectadores, testemunhas da "realidade relativamente autônoma", resta o mundo dos sentimentos e das emoções, como se não precisassem pensar e raciocinar sobre o assunto, já que isso está a cargo dos especialistas, que pouco acrescentam à discussão coletiva.

Com a ideia de que se deve atender as necessidades de todos, atrair a atenção de todos, os programas demonstram fatos que não devem chocar ninguém, que não envolvem disputa, que não dividem, que formem consenso, que interessem a todo mundo, mas de um modo tal que não toquem em nada de importante (BOURDIEU, 1997). Essa é a idéia de censura ${ }^{10}$, já que, mostrando coisas e construindo discussões superficiais, na verdade deixam de mostrar outras coisas e de suscitar outras discussões.

Algumas emissoras de televisão apelam ao emocional, à dramatização, ao sentimentalismo, pois é essa uma estratégia da utilização da imagem televisiva, o que parece evidente e imutável, porém como transpor o mundo do sensacionalismo e chegar ao mundo das idéias, do conhecimento e da crítica, é o ponto que se torna quase sempre impossível diante da velocidade das imagens e das informações proferidas

10. Um exemplo de censura realizada pela televisão pôde ser observado na preparação dos Jogos Panamericanos do Rio de Janeiro 2007, com a Rede Globo de Televisão, patrocinadora dos jogos, que não emitiu qualquer comentário sobre os escândalos de superfaturamento de obras, atraso nas conclusões das mesmas e o uso desmesurado do dinheiro público, já noticiados por outros meios de comunicação. 
nesses programas esportivos. A baixa frequência de jornalismo investigativo no Brasil, principalmente na área esportiva, demonstra o desmonte do lugar da reflexão séria e da crítica, em substituição ao jornalismo opinativo e das considerações pessoais dos agentes envolvidos.

Dessa forma, a opinião pública, definida como a expressão de uma reflexão individual ou coletiva sobre uma questão controvertida e concernente aos interesses coletivos realizada num espaço público (CHAUÍ, 2006), transforma-se em opiniões individuais sobre assuntos que acabam se privatizando. "Em lugar da opinião pública, tem-se a manifestação pública de sentimentos” (CHAUÍ, 2006, p. I0). Tudo se torna espaço para opiniões pessoais e individualizadas, que não interferem na vida política das pessoas e no bem-estar coletivo.

A esfera pública transforma-se radicalmente, deixando de ser um espaço coletivo de apropriações para ser um espaço de demonstrações dos interesses particulares. Contrariamente à ideia do Processo Civilizador, elaborada por Elias (1990, 1993), de que os sentimentos e as emoções seriam cada vez mais internalizados e individualizados" ${ }^{\prime \prime}$ num maior autocontrole do comportamento. Isto se confirma com as diversas câmeras espalhadas em domínios privados, e com o advento da internet, na qual a partir de um computador instalado em casa é possível comunicar-se e mostrar-se ao mundo. A intimidade, os segredos, antes restritos ao contexto da privacidade, assumem proporções de publicidade, de exteriorização do que era antes reservado.

Os jogadores de futebol que abrem as portas de suas casas para reportagens televisivas e os programas esportivos que se preocupam excessivamente com a intimidade dos atores esportivos, são retratos do que se tornou o debate público sobre o futebol. Um evento de natureza coletiva, sobre o qual todos poderiam participar, e que afetaria de alguma forma os interesses individuais dos participantes, transformam-se em um evento para sanar a curiosidade deles. Tal qual a lógica do mercado, o ambiente público torna-se uma questão de gosto pessoal, como a "livre" escolha de uma determinada marca ou de um canal de TV. Deixou de ser um espaço construído coletivamente e propício para discussões coletivas, para se tornar mais um espaço a ser escolhido, dentre tantos outros espaços privados que se interferem conforme a lógica do mercado.

I I. Há uma diferença entre o processo de individualização proposto por Elias e o individualismo existente atualmente. Enquanto a individualização é um processo móvel que desencadeia autocontroles individuais, num processo de internalização dos sentimentos, o individualismo (ou individualidade) é um conceito mais ideológico, relacionado ao modo de ser egocêntrico característico de nossa sociedade atual. Individualidade é o "dever ser" que denota um comportamento previsto; já a individualização é o "sendo" (LUCENA, 2002). 
Os programas televisivos analisados confundem-se, muitas vezes, com programas das celebridades do futebol. Eles não cansam de mostrar que, por meio da sua batalha e determinação, da sua astúcia e capacidade de driblar as armadilhas do destino, por meio da força individual e do talento natural, aquele indivíduo pobre, sem futuro, negligenciado pela sociedade, pode se tornar um ser reconhecido, a ser reverenciado, um exemplo de sucesso. Rico, famoso, com um super carro, uma supermulher, freqüentador de super festas, numa super vida, o mito da ascensão social por meio do esporte é constantemente transmitido por esses programas esportivos.

O futebol ganha importância e significado social, no discurso da mídia, exatamente por conseguir transformar a vida de crianças, por torná-las cidadãs, futuros campeões. Os exemplos a serem seguidos são sempre os Ronaldinhos, os Kakás, os Neymars, os Patos, os Gansos. A imensa maioria, na realidade, não possui outra opção a não ser olhar maravilhado para esses ídolos pela televisão. Por mais força de vontade e astúcia necessária, muito dificilmente se transformarão em ídolos esportivos. São obrigados a assistir à maravilha da vida irreal, enquanto sofrem as intempéries que a vida insiste em lhes infringir. Com as fontes de virtudes públicas quase inexistentes, só se pode procurar uma razão para os esforços vitais nos exemplos de sucesso e de superação individual e nas recompensas por tais virtudes.

Grande parte dos jogadores de futebol, famosos e exemplares (exemplares porque famosos) devido principalmente à baixa autonomia que possuem da própria vida e da própria carreira esportiva (vide a subordinação deles aos empresários DAMO, 2007), não aspiram ao poder de influenciar coletivamente, de prestar instruções em matéria de virtudes públicas, de contribuir significativamente para a vida daqueles que os assistem e os admiram, a não ser de expor a própria vida de sucesso para que os outros observem e admirem maravilhados.

Na pesquisa com os torcedores organizados (REIS, 2008), pode-se verificar que $77,3 \%$ dos entrevistados concordam que a mídia, de uma forma geral, contribui para violência existente no futebol; e 49, I \% dos entrevistados crêem que a mídia utiliza a violência para dar ibope ao seu programa, incitando a rivalidade e provocando os torcedores, como já foi constatado nos programas esportivos analisados aqui.

Outros 15,3\% dos entrevistados creem que a mídia contribui com a violência, principalmente quando fala mal dos torcedores organizados, com um tratamento equivocado ou parcial, ou quando generaliza as ações violentas para toda a torcida organizada.

Pudemos verificar esse comportamento da mídia principalmente no programa Mesa Redonda da TV Gazeta. Quando algum assunto relacionado à violência era tratado no programa, percebia-se o tom generalista e preconceituoso com o qual os torcedores organizados eram tratados. Numa reportagem, por exemplo, sobre 
um protesto dos torcedores em frente a um estádio de futebol, as imagens eram mostradas com uma legenda explicativa com os dizeres: "Protestos das torcidas assustam o futebol".

Dessa forma, o futebol sendo representado por meio da televisão, espetaculariza e dramatiza a violência que ocorre nos estádios, contribuindo para a imagem desgastada destes ambientes. Frases que escutamos, como "O estádio, como vocês podem ver, deixou há tempo de ser um lugar de gente boa ir" (Flávio Prado, TV Gazeta), contribuem para a própria violência tornar-se um simulacro televisivo, uma grande encenação televisiva, enquanto os estádios se tornam imageticamente ambientes perigosos, freqüentados por indivíduos perigosos, que supostamente só vão a esses locais para causar confusão, criar desordem e provocar violência, fazendo com que os indivíduos de "paz" fiquem em casa assistindo às partidas pela televisão.

Outras frases que pudemos escutar exemplificam bem a questão: "Futebol não é mais coisa de família" (Flávio Prado, TV Gazeta), "Esses marginais ganharam muito espaço no futebol” (Flávio Prado, TV Gazeta), "É igual a negociação com traficante na favela" (Flávio Prado, TV Gazeta). A forma descontextualizada com que a mídia trata a violência só contribui para sensacionalizá-la e banalizá-la, ajudando na deterioração dos espaços públicos e no incremento dos espaços privados. Para Freitas e Rigo (2009, p. I I 4), "a autoridade do discurso pronunciado pela imprensa esportiva confere um grau de apropriação e circulação significativo no meio sociocultural."

Nas entrevistas realizadas com os torcedores organizados, era comum mencionarem que a mídia não conhecia a realidade das torcidas organizadas, não sabiam quem eram seus integrantes, porém sempre que existia alguma briga no futebol, os torcedores organizados eram responsabilizados e chamados de "vândalos" ou "marginais".

As reportagens que foram feitas pelos programas, confirmaram o que os torcedores já haviam percebido. Em uma série de reportagens sobre a "saga corintiana na segunda divisão”, por exemplo, o programa Mesa Redonda (TV Gazeta) tentava se aproximar da realidade dos torcedores que, muitas vezes, cruzavam o Brasil inteiro para seguir seu time de coração, conforme pudemos ver nas matérias jornalísticas. Apesar de, algumas vezes, mostrar as dificuldades e os sofrimentos que muitos torcedores passam para assistir seus clubes nos estádios brasileiros, eles mostravam na maioria das vezes imagens de conflitos entre torcedores ou policiais, e buscavam generalizar aquilo para toda a torcida organizada, responsabilizando-os indiscriminadamente por qualquer conflito existente.

Outra reportagem, do programa Terceiro Tempo (TV Band), também causou o mesmo resultado. Chamada pelo apresentador, que dizia que iria "conhecer os personagens do Pacaembu", ele generalizava a opinião da torcida organizada a partir 
de fragmentos de entrevistas com alguns integrantes (lembremos que a televisão cria uma realidade relativamente autônoma).

Dessa forma, o que ocorre dentro dos estádios, ou nos seus arredores, inclusive a violência, também é descontextualizado ao telespectador, que tem a impressão distorcida sobre o que acontece na realidade. É como se a violência no futebol não existisse antes de ser televisionada, pois somente dessa forma ela se torna real.

Alguns autores ${ }^{12}$ já demonstraram a existência de atos violentos bem antes do período atual. Elias e Dunning ( 1992 ) afirmam que o esporte moderno tem, como principal característica, o aumento expressivo do autocontrole dos indivíduos e a diminuição da violência em sua prática.

Porém a mídia, com sua ausência de referência temporal, ou acronia (Chauí, 2006), trata como se vivêssemos o período de barbárie no futebol, como se a violência não tivesse precedente, e que seus atores fossem somente grandes "delinqüentes", perversos, que saíram de parte nenhuma, e com a única intenção de ameaçar a vida das pessoas "honestas" e de "bem". Os estudos de Reis (2006) demonstram como a violência no futebol se transformou, e como ela possui raízes muito mais profundas do que o simples tratamento dado pelos meios de comunicação. Porém, a forma descontextualizada e banalizada com que a televisão trata a violência somente colabora para transformar o estádio de futebol, um ambiente construído historicamente para fins públicos, em um espaço potencialmente violento, procurado por indivíduos que desejam se manifestar de forma violenta.

Outro ponto a ser realçado, na análise dos programas, é a constante polarização do discurso dos especialistas. Quando mostrada alguma confusão presente nos estádios, ou nos seus arredores, o discurso dos especialistas vai ao contrário do que a maioria dos torcedores detecta; de que a mídia, em especial a televisão, contribui para a violência no futebol. Além de negar que a mídia possa, de alguma forma, ter uma influência, os especialistas tentam sempre menosprezar seus próprios poderes, ou então menosprezar a importância do futebol, com frases como "Futebol no fundo, minha gente, é uma grande brincadeira!".

A atitude é polarizada e contraditória, pois, para garantir a audiência aos seus programas esportivos, a ênfase da TV é sempre de espetacularizar e exacerbar a paixão clubística, com seus excedentes e suas rivalidades. Para garantir a identidade com a transmissão televisiva e, logicamente, com seus produtos, a televisão supervaloriza o aspecto simbólico do futebol. E torna-se contraditória, quando reprime os torcedores que assumem esse aspecto simbólico em suas vidas, agindo, muitas vezes, de forma violenta. "É só um esporte, minha gente"; "é só futebol", são falas então proferidas, desconsiderando o que o "só" futebol representa para essas pessoas.

12. Murphy, Dunning e Willians (1994) e Pereira (2000). 


\section{CONCLUSÕES}

A pesquisa comprovou que é por meio da exacerbação do sentido dos torcedores, apelando para o pertencimento de seus clubes, que a televisão garante audiência e, consequentemente, possíveis consumidores para os produtos ofertados nos merchans das "mesas redondas".

De certa forma, as análises desses programas esportivos convergem com as declarações que encontramos entre os entrevistados de Reis (2008), pois há uma forte tendência de estigmatização dos torcedores organizados como vândalos, vagabundos e marginais, assim como sua generalização, como se pertencer a uma torcida organizada fosse determinante para ser um transgressor a ser banido da sociedade, o que só contribui para uma visão fragmentada da violência no futebol e dos torcedores.

A pesquisa também comprovou que há uma lógica interna a esses programas, que independe da emissora de televisão, principalmente quando recorrem a anúncios e apelos sobre produtos de toda natureza como estratégia de marketing das emissoras desses programas esportivos, seja para vincular a marca aos "esportistas" e, com isto, conquistar novos consumidores, ou simplesmente para aumentar sua receita. Entendemos também que o apelo ao conforto da casa, e os problemas constantemente banalizados para a vivência do futebol nos espaços públicos, cria a falsa ilusão que o único espaço seguro para a assistência do futebol é o ambiente privado, dentro de casa. Dessa forma, os ambientes públicos tornam-se ainda mais deteriorados, e a discussão política e a opinião pública são destruídas pela confusão entre a realidade e seu simulacro televisivo.

Conclui-se que a compreensão desse processo da televisão com o futebol não deve ser visto como uma mera mercadorização do esporte, como uma análise fria econômica poderia nos levar, mas sim como uma mistura entre o processo simbólico existente no futebol e sua latente transformação em mercadoria.

The supposed forums of football discussion on television: the "mesas redondas"

ABSTRACT: This article analyzes the sports programs which are supposedly the forums for discussion of football. To this end we chose the programs "Terceiro Tempo" from "Rede Bandeirantes" and "Mesa Redonda" from TV Gazeta, because they are the most relevant programs of this gender, and because they are constantly cited in interviews (REIS, 2009). We analyzed the structure of presentation of the programs televised in 2008 during the performance of the Brazilian football Championship, especially in regard to its composition with the merchandising. We concluded that the understanding of this process should not be seen simply as a commodification of sport, but as a mix between symbolic process that exists 
in football and its latent modification in merchandising. These programs also contribute to a fragmented view of the violence of football and the fans.

KEYWORDS: football; television; sports programs; merchandising.

Las supuestas áreas de discusión del fútbol en la televisión: las "mesas redondas"

RESUMEN: Este articulo analisa los programas desportivos que supuestamente son los foros para la discusión de fútbol. Com este fin, hemos elegido el programa "Terceiro Tempo" de la Rede Bandeirantes de Televisão y "Mesa Redonda" de la TV Gazeta, ya que son más relevantes en el género y porque son constantemente citados en las respuestas de los encuestados por Reis (2008). Hemos analizado la estrutura de la presentación de los programas emitidos en 2008 durante el transcurso del Campeonato Brasileiro, especialmente su composición con el merchandising. Llegamos a la conclusión de que la comprensión de este proceso no debe ser visto como uma mera mercantilización del deporte, sino como una mezcla entre el proceso simbólico que existe en el fútbol y su mercantilización latente. Estos programas también contribuyen a uma visión fragmentada de la violência em el fútbol y de los fans.

PALABRAS-CLAVE: fútbol; televisión; programas desportivos; merchandising.

\section{REFERÊNCIAS}

BETTI, M. A janela de vidro: esporte, televisão e educação física. Campinas: Papirus, 1998.

BOURDIEU, P. Questões de sociologia. Rio de Janeiro: Marco Zero, 1983.

Sobre a televisão. Rio de Janeiro: Jorge Zahar, 1997.

CHAUÍ, M. Simulacro e poder: uma análise da mídia. São Paulo: Fundação Perseu Abramos, 2006.

DAMO, A. S. A magia da seleção. Revista Brasileira de Ciências do Esporte, Campinas: Autores Associados, v. 28, n. I, p. 73-90, 2006.

Do dom à profissão: a formação de futebolistas no Brasil e na França. São Paulo: Hucitec, ANPOCS, 2007.

DUNNING, E. El fenómeno deportivo: estudios sociológicos em torno al deporte, la violencia y la civilización. Barcelona, Paidotribo, 1999.

ECO, U. Viagem na irrealidade cotidiana. Rio de Janeiro: Nova Fronteira, 1984.

ELIAS, N. O processo civilizador: formação de estado e civilização. Rio de Janeiro: Jorge Zahar, 1990. v. 2.

O processo civilizador: uma história dos costumes. Rio de Janeiro: Jorge Zahar, 1993. v. I.

; DUNNING, E. A busca da excitação. Lisboa: Difel, 1992. 
ESCHER, T. A. Futebol e violência: a implementação do estatuto do torcedor - um estudo de caso. 2004. 94 f. Trabalho de Conclusão de Curso (Graduação) - Faculdade de Educação Física, Universidade Estadual de Campinas, Campinas, 2004.

FREITAS, G. S.; RIGO, L.C. Discursos de uma derrota: um estudo da produção discursiva sobre a eliminação da Seleção Brasileira na Copa do Mundo de 2006. Revista Brasileira de Ciências do Esporte, Campinas, v. 30, n. 3, p. I I I-125, maio 2009.

GASTALDO, E. L. "Os campeões do século": notas sobre a definição da realidade no futebol espetáculo. Revista Brasileira de Ciências do Esporte, Campinas, v. 22, n. I , p. I 05- I 24, set. 2000.

GIULIANOTTI, R. Sociologia do futebol: dimensões históricas e socioculturais do esporte das multidões. São Paulo: Nova Alexandria, 2002.

LUCENA, R. F. Elias: individualização e mimesis no esporte. In: PRONI, M. W.; LUCENA, R. F. (Org.). Esporte: história e sociedade. Campinas: Autores Associados, 2002.

MATTELART, A. O carnaval das imagens: a ficção na TV. São Paulo: Brasiliense, 1989.

MURPHY, P.; DUNNING, E.; WILLIANS, J. Futebol no banco dos réus. Oeiras: Celta, 1994.

PEREIRA, L. A. M. Footballmania: uma história social do futebol no Rio de Janeiro (19201938). Rio de Janeiro: Nova Fronteira, 2000.

PIMENTA, C. A. M. Torcidas organizadas de futebol: identidade e identificações, dimensões cotidianas. In: ALABARCES, P. (Comp.). Futbologias: fútbol, identidad y violencia en América Latina. Buenos Aires: Clacso, 2003.

REIS, H. H. B. Futebol e violência. Campinas: Autores Associados, 2006.

. A caracterização do torcedor organizado e a mídia esportiva". Brasília: Ministério do Esporte, 2008.

ROCCO JUNIOR, A. J. Novas tecnologias e as torcidas virtuais: a transformação da cultura do futebol no século XXI. In: MARQUES, J. C.; CARVALHO, S.; TOLEDO, V. R. (Org.). Comunicação e esporte: tendências. Santa Maria: Palloti, 2005.

TOLEDO, L. H., Lógicas no futebol. São Paulo: Hucitec: Fapesp, 2002.

Recebido: 06 jul 2010 Aprovado: 02 mai 201 I

Endereço para correspondência: Thiago Aragão Escher Rua José de Toledo, 17 ap. 34 Jardim do Trevo CEP: 13040-034 Campinas, SP, Brasil 